\title{
APRENDENDO INGLÊS A DISTÂNCIA: UMA ANÁLISE DE PRÁTICAS DE SPEAKING NA LICENCIATURA EM LETRAS PELA UFC VIRTUAL
}

\author{
https://doi.org/10.29327/3860.11.20-3
}

\author{
Karoline Zilah Santos ${ }^{1}$ \\ Karlucy Farias de Sousa ${ }^{2}$
}

\section{RESUMO}

Aprender a falar inglês pode ser um desafio na Educação a Distância $(\mathrm{EaD})$, devido à necessidade de adaptações metodológicas para quem ensina, bem como da autonomia de quem aprende. Este trabalho investiga como o Instituto Universidade Virtual (UFC Virtual), ligado à Universidade Federal do Ceará, em parceria com a Universidade Aberta do Brasil (UAB), possibilita que os alunos da Licenciatura em Letras - Língua Inglesa e suas Literaturas - aprendam a habilidade de produção oral (speaking). Nesse estudo qualitativo, realizamos uma observação participante e acessamos o Ambiente Virtual de Aprendizagem (AVA) Solar, a fim de analisar as ferramentas de comunicação disponíveis para que os discentes conversassem em inglês entre si e com o tutor. O corpus é a disciplina Língua Inglesa 3A - Produção e Compreensão Oral, oferecida no terceiro semestre do curso, no período de março a maio de 2018. Para isso, verificamos quais tipos de interação foram oferecidos na plataforma: síncronas (em tempo real); assíncronas (em horários diferentes); ou multissíncronas (combinando as duas formas). Pesquisamos, também, os roteiros disponibilizados para as tarefas de speaking, em busca de identificar se os alunos poderiam praticar conversações autênticas, ou se repetiam frases previamente formuladas. Os resultados mostram que os aprendizes não tiveram oportunidades para se comunicar em inglês em tempo real a distância pelo Solar, nem de receber correções ou comentários síncronos do tutor. Confirmamos, ainda, que as tarefas roteirizadas poderiam dar margem para que os alunos não se engajassem em diálogos espontâneos.

Palavras-chave: Educação a Distância; Aprendizagem de Línguas à Distância; Aprendizagem de Língua Inglesa; Desenvolvimento de Oralidade.

\footnotetext{
${ }^{1}$ Especialista no Ensino de Língua Inglesa pela Universidade Estadual do Ceará (Fortaleza/Brasil). Graduanda em Letras - Língua Inglesa e suas Literaturas, pela Universidade Federal do Ceará (Fortaleza/Brasil). Bacharel em Comunicação Social (habilitação em Jornalismo) pela Universidade Federal da Paraíba (João Pessoa/Brasil). Professora-bolsista de Língua Inglesa no Programa Idiomas sem Fronteiras, na Universidade Federal do Ceará.

${ }^{2}$ Mestre em Linguística Aplicada (Concentração em Estudos da Linguagem) pela Universidade Estadual do Ceará (Fortaleza/Brasil). Pós-graduanda em Linguagem, Tecnologia e Ensino pela Universidade Federal de Minas Gerais (Belo Horizonte/Brasil). Professora de Língua Inglesa do Instituto Federal de Educação, Ciência e Tecnologia do Ceará (IFCE-Campus Limoeiro do Norte).
} 


\title{
DISTANCE ENGLISH LEARNING: AN ANALYSIS OF SPEAKING PRACTICES IN A LICENTIATE DEGREE PROGRAM AT UFC VIRTUAL
}

\begin{abstract}
Learning how to speak English might be challenging in a distance education program, due to its necessity of methodological adaptations to those who teach, as well as to the autonomy necessary to those who learn. This work aims at investigating how the Virtual University Institute (UFC Virtual), connected to the Federal University of Ceará in partnership with The Open University of Brazil (UAB), enables licentiate degree students to learn how to speak English. In this qualitative study, we develop a participant observation, accessing the website Solar, a Virtual Learning Environment (VLE), in order to analyze the resources available for students to chat between them and with their tutor. The corpus of this research is the English Language - Oral Production and Oral Comprehension course, offered during the third term of the undergraduate program, between March and May 2018. We verify which type of interactions are offered in the platform: synchronous (communication in real time); asynchronous (learning opportunities that can be accessed at any time); or multi-synchronous (combining the two forms of delivery). We exam, as well, the scripts provided during the speaking tasks, aiming at identifying if the students would practice authentic conversations, or if they would repeat previously formulated phrases. The results show that the learners did not have opportunities to communicate in English in real time at a distance at Solar, nor to receive corrections or synchronic feedback from the tutor. We also confirm that the scripted tasks could allow the students to not engage in spontaneous dialogues.
\end{abstract}

Keywords: Distance Education; Distance Language Learning; English Language Learning; Speaking Skill.

\section{INTRODUÇÃO}

A Educação a Distância $(\mathrm{EaD})$ é uma alternativa para descentralizar a oferta de cursos de licenciatura em Língua Inglesa (LI) das capitais para as cidades do interior brasileiro. Um dos princípios da $\mathrm{EaD}$ é disseminar o ensino em regiões distantes e socialmente desiguais. Atualmente, são oferecidas várias opções de graduações a distância em Instituições de Ensino Superior (IES) públicas. Um exemplo é a Universidade Federal do Ceará (UFC), que fundou em 2003 o Instituto Universidade Virtual (conhecido como UFC Virtual), em parceria com a Universidade Aberta do 
Brasil (UAB). Entre os cursos, está a Licenciatura Plena em Letras - Língua Inglesa e suas Literaturas. Além das aulas à distância, a instituição tem o apoio de vinte e cinco polos em municípios cearenses para atividades presenciais.

Tratando especificamente da Licenciatura em Letras - Inglês, na modalidade à distância da UFC Virtual, investigamos, neste artigo, como ocorre a aprendizagem de produção oral em Língua Inglesa (LI), também tratada neste trabalho pelo termo speaking, a habilidade de falar utilizando a língua estrangeira. A principal questão que motivou essa pesquisa foi: quais formas de ensino de línguas à distância podem ser usadas para que os alunos desenvolvam suas habilidades orais no curso? Nosso ponto de partida é um breve histórico do ensino de LI nessa modalidade no Brasil e na UFC Virtual. Abordamos alguns conceitos de EaD (WHITE, 2003; PAIVA, 2013, 2001, 1999), pontuamos a legislação referente ao ensino semipresencial (BRASIL, 2017), e apresentamos o curso de Letras - Inglês na UFC Virtual, contemplando sua proposta pedagógica, o papel de cada agente envolvido na rotina da sala de aula virtual e o programa da disciplina (UFC, 2013).

Acompanhando a transformação da sala de aula física em virtual, surge também um desafio para o professor, o "reletramento digital" (LEFFA, 2016, p. 141), uma necessidade de adaptação de metodologias de ensino-aprendizagem conforme a inserção das Tecnologias da Informação e Comunicação (TICs) nesse processo. Assim, nos deparamos com alguns problemas na transição do ensino presencial tradicional para a EaD (SHELLEY; MURPHY; WHITE, 2013), tais como a sensação de isolamento dos alunos, desmotivação, necessidade de autodisciplina e autonomia (REINDERS; WHITE, 2016), redução das oportunidades para aprender de forma incidental e da mediação do professor em tempo integral. Mostra-se necessária, então, a implementação de atividades mais interativas e atraentes, conforme as afinidades culturais dos alunos (PAIVA, 2013), e que sejam também estimulantes para possibilidades reais de comunicação no contexto social do grupo (PAIVA, 2001).

Em seguida, analisamos quais são as ferramentas disponíveis para interações entre alunos, tutores e professores no curso a distância, dentro do Ambiente Virtual de Aprendizagem (AVA) da instituição, a plataforma Solar. Categorizamos esses recursos de comunicação conforme as possibilidades de interações entre os sujeitos (WHITE, 2003): se são recursos síncronos (comunicações em tempo real), assíncronos (em 
horários diferentes), ou multissíncronos. Para isso, observamos, descrevemos e analisamos as atividades que foram desenvolvidas a distância, identificando vantagens e desvantagens de cada uma. Apontamos, então, algumas influências dessas ferramentas no aprimoramento da oralidade dos alunos.

Ao analisar as tarefas de speaking propostas no curso de Letras - Inglês, questionamos, ainda, se elas proporcionam o desenvolvimento de micro-habilidades da fluência oral (BROWN; LEE, 2015), dentro da aprendizagem de speaking a distância, para evitar discursos roteirizados - seguindo o pressuposto de que oralização de textos escritos não representa espontaneidade e criação de discurso (OLIVEIRA, 2015).

Nesse trabalho, optamos por desenvolver uma pesquisa qualitativa (GIL, 2017), na qual pudéssemos observar, refletir e interpretar os dados à medida em que eles surgiam. Adotamos como metodologia uma pesquisa de campo exploratória, por se tratar de uma investigação que permite ao pesquisador formular hipóteses e familiarizarse com um ambiente, fato ou fenômeno, para desenvolver uma pesquisa precisa (LAKATOS; MARCONI, 2017). A coleta de dados foi feita a partir de uma observação participante, que implica na incorporação do pesquisador à comunidade estudada, atuando nas atividades. A participação, neste caso, justifica-se pelo fato de uma das autoras da pesquisa ser aluna do referido curso e ter tido acesso à disciplina em questão no Solar.

A pesquisa aconteceu no primeiro semestre de 2018, durante a disciplina Língua Inglesa 3A - Compreensão e Produção Oral, que é oferecida no terceiro termo do curso, e foi ministrada de $1^{\circ}$ de março a 10 de maio de 2018. Procuramos observar nesse AVA quais eram os tipos de ferramentas de interação disponíveis para que os alunos pudessem desenvolver suas competências orais. Consultamos, também, os documentos no formato Word, onde eram requisitadas as tarefas de speaking, com o objetivo de analisar as orientações que foram dadas para que os alunos falassem em inglês e fossem avaliados pelo tutor a distância.

As consultas foram realizadas dentro do endereço eletrônico Solar (virtual.ufc.br), ao qual apenas alunos, tutores, professores e administradores ligados aos cursos da UFC Virtual têm acesso. Vale ressaltar que o curso é semipresencial; portanto, além das aulas e das tarefas disponíveis no Solar, uma porcentagem das 
atividades ocorreu presencialmente nos polos municipais. No entanto, essa pesquisa se restringe a estudar apenas os trabalhos feitos à distância. Portanto, as aulas presenciais não foram avaliadas.

Para realizarmos uma análise sobre as práticas de produção oral a distância na Licenciatura em Letras - Língua Inglesa, na UFC Virtual, é preciso compreender as origens dessa modalidade de ensino no Brasil, bem como o contexto no qual esse curso foi criado. Sendo assim, realizamos uma pesquisa abrangendo o Projeto Pedagógico (UFC, 2013) do curso de graduação em questão, buscando compreender o cenário e as justificativas para sua abertura, bem como a ementa específica da disciplina que avaliamos nesse trabalho. Em seguida, levantamos informações sobre as adaptações necessárias para que o tradicional ensino de Língua Inglesa presencial seja bemsucedido na modalidade à distância. Vemos que, apesar da inovação dos métodos de ensino e da autonomia do aprendiz, a comunicação entre alunos e professores continua sendo indispensável. Dessa forma, investigamos quais tipos de interações são possíveis através de um Ambiente Virtual de Aprendizagem (AVA), a plataforma na qual são disponibilizados os conteúdos para os discentes.

\section{LICENCIATURA EM LÍNGUA INGLESA NA UFC VIRTUAL: BREVE HISTÓRICO}

Mesmo diante da popularidade atual dos cursos de Educação a Distância, alguns autores concordam que não existe um conceito único para o termo EaD. Paiva (1999) já mencionava a EaD como um processo no qual os meios de comunicação quebram barreiras de tempo e espaço para auxiliar a interação entre as fontes de informação e o sistema educacional, tornando possível a autonomia do aprendiz para estudar com independência e flexibilidade. Mais adiante, White (2003) apresenta uma compilação de conceitos que se complementam e que indicam uma ampla variedade de abordagens, todas enfatizando a distância geográfica e de tempo entre professor e aluno. Ela considera esses programas como sistemas nos quais os aprendizes podem estudar conforme suas próprias disponibilidades de tempo, no lugar de sua escolha, sem exigir contato face-a-face com um professor. A autora também cita a necessidade de um 
planejamento diferenciado, com metodologias de ensino e de comunicação adequadas para que a mediação entre aprendizes e docentes facilite o processo educacional.

Essa modalidade de ensino foi mencionada pela primeira vez na legislação brasileira em no artigo 80 da Lei de Diretrizes e Bases da Educação Nacional (LDBE), a Lei n. 9.394 (BRASIL, 1996). No texto, ficou estabelecido que o Poder Público incentivaria o desenvolvimento de programas de Educação a Distância em todos os níveis e modalidades de ensino. Anos depois, o Decreto n. 5.622 (BRASIL, 2005) regulamentou o artigo 80, caracterizando a $\mathrm{EaD}$ como modalidade didático-pedagógica ocorrida por meios de Tecnologias de Informação e Comunicação (TICs), na qual estudantes e professores desenvolveriam atividades em lugares ou tempos diferentes. $\mathrm{Na}$ ocasião, foram estabelecidas orientações sobre encontros presenciais, avaliações dos alunos e credenciamentos de instituições.

A atualização mais recente relacionada à $\mathrm{EaD}$ está no Decreto n. 9.057 (BRASIL, 2017a), que estabelece a necessidade de pessoal qualificado e de políticas de acesso, com acompanhamento e avaliação que sejam compatíveis à modalidade. Nesse decreto, também ficou decidido que as IES podem ampliar a oferta de cursos superiores de graduação e pós-graduação a distância, mesmo sem tê-los na modalidade presencial.

O Instituto Universidade Virtual (UFC Virtual) está vinculado diretamente à Reitoria da UFC e atua como sua unidade de Educação a Distância desde 2003, em parceria com a Universidade Aberta do Brasil (UAB). A instituição propôs a abertura do Curso de Licenciatura Plena em Letras - Língua Inglesa e suas Literaturas no ano de 2013, algo consideravelmente recente, visto que Paiva (1999) recomendava que as potencialidades da Rede Mundial de Computadores deveriam ser utilizadas em nome de melhorias na Educação. A pesquisadora já vislumbrava na Internet uma oportunidade para a aprendizagem de línguas estrangeiras mediante a integração de dados, imagens e sons, bem como ao processo de facilitação do acesso à informação, de forma a quebrar barreiras de tempo e espaço.

Entre as justificativas presentes no Projeto Pedagógico do curso (UFC, 2013), constam: o papel da língua inglesa como língua franca no mundo, tendo um número de falantes não-nativos que ultrapassa a quantidade de falantes nativos e o aumento da demanda por profissionais qualificados para o ensino do idioma. Na época em que o projeto foi redigido, estava em vigor o Artigo 26, parágrafo quinto, da LDBE (BRASIL, 
1996), que estabelecia o ensino obrigatório de pelo menos uma língua estrangeira moderna a partir da quinta série do então Ensino Secundário (equivalente, hoje, ao sexto ano do Ensino Fundamental). A escolha do idioma ficava a critério da comunidade escolar, de acordo com suas possibilidades. Nessa conjuntura, reforçou-se a preocupação com o número insuficiente de profissionais licenciados para ensinar inglês nas escolas públicas e particulares, o que impulsionou a abertura do curso semipresencial pela UFC Virtual. Posteriormente, a Lei no 13.415 (BRASIL, 2017b) alterou aquele parágrafo e instituiu a obrigatoriedade do inglês no currículo a partir do sexto ano do Ensino Fundamental até o último ano do Ensino Médio.

Outra justificativa para a oferta do curso na modalidade semipresencial seria o índice de evasão nos cursos de licenciatura. A comissão da UFC Virtual apontou como possível causa a impossibilidade de o aluno conciliar as atividades de estudante com as de profissional, bem como a distância dos grandes centros, pois os custos com tempo e investimento financeiro para viajar acabam inviabilizando o seguimento dos estudos.

Desta forma, a Licenciatura em Letras - Inglês foi oferecida a distância, com o apoio de polos presenciais em doze municípios do Ceará, na expectativa de reduzir as limitações geográficas para que essa formação chegasse ao público-alvo. Com a "desterritorialização" (UFC, 2013, p. 20) das informações entre os centros de produção de conhecimento, os professores, os tutores e os alunos, foi criado, então, o AVA Solar, no qual os participantes ultrapassariam as barreiras das situações de aprendizagem exclusivamente presenciais e teriam acesso a novos conteúdos e novas formas de interação online, por meio de canais de bate-papo, fóruns, textos coletivos, videoconferências e midiateca.

O Curso de Letras a distância não acontece $100 \%$ virtualmente. O Projeto Pedagógico deixa claro que momentos presenciais são obrigatórios, em conformidade com o Decreto $\mathrm{n}^{\circ} 5.622$ (BRASIL, 2005). Destarte, ficou determinado que as avaliações ocorreriam presencialmente, bem como uma porcentagem dos momentos de aulas deveria ser presencial ou através de videoconferência (webconference), para que os tutores pudessem orientar seus alunos em relação aos conteúdos ministrados nas disciplinas. A proposta é de que, nessas interações, os envolvidos possam continuar os diálogos iniciados em meio virtual, estimulando discussões e amadurecendo ideias. 
Na proposta de abertura do curso, também são especificados os papeis de cada agente formador (UFC, 2013). O professor titular é aquele que estabelece os objetivos acadêmicos, atualiza o conteúdo programático, desenvolve estratégias didáticometodológicas, elabora o material didático, define as diretrizes de execução do curso e propõe critérios de avaliação do desempenho do aluno. Ele pode eventualmente prestar assessoria ao professor formador. Esse, por sua vez, acompanha o desenvolvimento do curso e das atividades realizadas pelos tutores a distância, que são os responsáveis pelo contato presencial com os alunos no polo e nos Fóruns, assessorando-os, dando aulas presenciais, aplicando provas e as corrigindo. Já os tutores presenciais têm a função de auxiliar os alunos em dificuldades vivenciadas no curso a distância, promovendo a integração entre eles, orientando em relação à agenda de atividades e em pesquisas práticas ou de campo, contatando os tutores a distância ou professores especialistas para resolver problemas de ordem pedagógica ou administrativo-acadêmica.

Ainda conforme o Projeto Pedagógico (UFC, 2013), além das aulas marcadas nos polos, alunos e tutores também têm encontros no Solar por meio de videoconferência. A ferramenta permite contato visual e sonoro entre os participantes que estão em lugares diferentes, de forma a economizar tempo, recursos e facilitar o diálogo em tempo real. É possível, inclusive, compartilhar informações através de links de websites, transferir arquivos e fazer apresentações em Power Point. A duração média estabelecida para as videoconferências é de duas horas. Os alunos podem ter acesso a esse recurso nos laboratórios dos polos nos municípios conveniados ou através de computadores em suas residências ou em outro local com acesso à Internet.

A disciplina analisada neste artigo se chama Língua Inglesa 3A: Compreensão e Produção Oral, com duração de 64 horas, pertencente à grade curricular obrigatória do terceiro semestre do Curso. Seu ementário prevê conteúdos que orbitam o tema: "Estudo das situações prático-discursivas da língua inglesa, mediante estruturas léxicogramaticais de nível intermediário para o desenvolvimento das habilidades comunicativas de ouvir e falar, sensibilizando o aluno para os aspectos sócio-culturais e interculturais das comunidades falantes desta língua" (UFC, 2013, p. 57).

Os conteúdos informados no programa do curso são: expressões de tempos verbais no Futuro; Futuro com going to; formas do Presente usadas no Futuro; expressando opiniões, concordância e discordância; palavras interrogativas (question 
words); Futuro usando will; expressões do tempo Passado; formação e ordem de adjetivos; como expressar sentimentos e reações; o Passado do verbo to be; o Passado Simples (simple past) da expressão There to be; formação de substantivos para nomear trabalhos e profissões; formação de advérbios; e o passado simples de verbos regulares e irregulares. Adiante, vemos como esse tipo de conteúdo pode ser abordado em um curso de língua estrangeira a distância, mediante o uso de TICs.

\section{"RELETRAMENTO DIGITAL" E ADAPTAÇÕES NO ENSINO A DISTÂNCIA}

Em se tratando de estudos de línguas estrangeiras, Leffa (2016, p. 141) argumenta que o docente desta área pode estar em seu "melhor momento histórico" devido à necessidade que as pessoas têm de saber falar outros idiomas: "o computador pode ser extremamente útil no trabalho do professor e deve ser visto como um meio, um instrumento de mediação entre o professor, seus colegas e seus alunos”. Desta forma, parte do desafio do professor está no "reletramento digital" (LEFFA, idem): ele precisa acompanhar a evolução das tecnologias no ensino e conceber a Educação como geração de novos saberes, em vez de transmissão de conhecimentos.

De que forma essa atualização do docente surge no cenário da EaD? A atuação do professor/tutor em mídias digitais (como os AVAs) envolve não somente a realização de tarefas e outros processos relacionados à aprendizagem. Seu papel também engloba monitorar e auxiliar em problemas que possam derivar desses processos e, para isso, utilizar as próprias TICs para apoiar sua interação com os estudantes, conforme afirmam Hack e Negri (2010):

Na educação presencial, o quadro negro, o giz, o livro, entre outros, são instrumentos pedagógicos que fazem a ponte entre o conhecimento e o aluno. Na Educação a Distância, a interação com o professor passa a ser indireta, por isso torna-se necessária a utilização de uma combinação de suportes técnicos de comunicação. As TIC possibilitam formas inéditas de interação midiatizada e de interatividade no processo de ensino e aprendizagem ao combinar a flexibilidade da interação humana com a independência no tempo e no espaço, sem por isso perder velocidade, como por exemplo, ao utilizar o $e$-mail, as listas e grupos de discussão ou as páginas da web. (HACK; NEGRI, 2010, p. 92, grifos dos autores) 
Paiva $(2013,2001)$ defende que se aprende língua inglesa através de seu uso, em vez de apenas incentivar o aluno a estudar frases pré-estabelecidas e descontextualizadas. Sua orientação é de que o professor se reeduque para derrubar as paredes da sala de aula tradicional para adentrar o ciberespaço, assumindo, então, a postura de interagir com os alunos em inglês de forma espontânea, como compartilhar material autêntico a exemplo de outros sites.

Quando motivado, o aluno usa a língua estrangeira para outras finalidades fora da sala de aula, como ouvir música, compreender diálogos em filmes e brincar com jogos eletrônicos. Interagir com estrangeiros seria a última das prioridades. O problema estaria no incentivo dado pela escola, pois a língua seria abordada de forma artificial nas atividades sobre itens gramaticais ou por meio de traduções de textos escolhidos pelo professor sem que os alunos tenham interesse nos assuntos. "Frases soltas em exercícios do tipo 'passe para a negativa ou passe para o plural' não constituem enunciados da vida real, como o famoso 'The book is on the table' ou 'The cat is under the table" (PAIVA, 2013, p. 33).

A autora indica algumas alternativas para despertar o interesse dos alunos, como trabalhar com gêneros textuais que abordem assuntos de interesse do público (esportes, cinema e música), com tamanho e nível de dificuldade compatíveis com o nível linguístico do grupo. O uso da língua oral poderia ser estimulado com pequenas apresentações artísticas, encenações, entrevistas com colegas, cantando ou interagindo em jogos. Outras dicas interessantes que servem como incentivo: trabalhar com músicas e deixar os alunos cantarem, apresentar cenas de filmes com legendas em inglês e até desafiar o grupo a encená-las com base em roteiros que podem ser encontrados na Internet. Conforme orienta Paiva (2013), persistir em memorizações de regras gramaticais e em exercícios descontextualizados poderia desmotivar os alunos.

Tratemos, agora, dos desafios da aprendizagem de língua estrangeira na EaD. Conforme visto anteriormente, o ensino de LI na modalidade a distância pela UFC Virtual é promovido, na maior parte do tempo, por meio de atividades online no Solar, além da carga horária específica para encontros presenciais. No caso da disciplina Língua Inglesa 3A, foram destinadas oito horas/aula para a tutoria nos polos presenciais. Não se pode negar que a dinâmica do ensino a distância é diferente do ensino presencial; são necessárias adequações para que os alunos oriundos do ensino 
presencial tradicional na Educação Básica se familiarizem com as novas rotinas no AVA e se habituem a não mais enxergar a sala de aula como um lugar delimitado por quatro paredes.

Reinders e White (2016) indicam que aspectos importantes da experiência do ensino de línguas são modificados no contexto da $\mathrm{EaD}$, o que impõe novos desafios aos aprendizes. Algumas das limitações sofridas pelos alunos e citadas por ela são a redução das oportunidades de suporte imediato, orientação, interatividade, comentários (feedback), correções e de aprendizagem incidental/informal, que ocorre de forma espontânea em alguma tarefa ou relação interpessoal. Assim, deve haver uma preocupação, no ensino de línguas a distância, em investir mais em modelos síncronos de comunicação, para que professores e alunos trabalhem juntos em um mesmo espaço virtual e ao mesmo tempo, facilitando a interação, o feedback, e respondendo perguntas para fazer ajustes que se encaixem nas necessidades dos aprendizes.

Conforme Shelley, Murphy e White (2013), quando o aluno começa a usar um ambiente de aprendizagem a distância, ele se depara com novas condições, tais como: o isolamento (a falta de contato pessoal com os pares); a falta de acesso às interações regulares em sala de aula com as quais já estava acostumado na Educação Básica; problemas de motivação e de autodisciplina; menos oportunidades de compartilhar suas percepções através de contatos informais, ou de aprender de forma incidental; maiores frustrações devido a desencontros de informações.

Um dos aspectos mais complexos é a ausência da mediação do professor em tempo integral durante o curso, o que resulta na necessidade de o próprio aluno estabelecer regras para o seu comportamento diante do processo de aprendizagem, bem como desenvolver habilidades que combinem os seus objetivos com os dispositivos de aprendizagem disponíveis. Para a pesquisadora, parte importante do trabalho do professor é estabelecer um clima social positivo e coeso na sala. Como parte disso, alunos e professores de línguas estrangeiras fazem uso de uma série de sugestões sociais, linguísticas e contextuais para compreender os conteúdos e contribuir para a dinâmica da sala de aula. A ausência desse contato físico na EaD pode significar uma perda dessas sugestões que ocorrem nos momentos de interação, prejudicando a manutenção do engajamento do público. 
White (2003) lembra que essa modalidade de ensino reduz o imediatismo do professor, que pode ser explicado como os comportamentos verbais e não-verbais e as rotinas que podem ajudar a estabelecer relações entre professores e aprendizes e que são importantes na criação de um ambiente de aprendizagem. Portanto, a ausência dessas dicas visuais - como acenos, gestos e contato visual - acaba se tornando um desafio nas conversações em grupo nos AVAs (em uma webconferência, por exemplo), pois pode afetar o processo de troca de turnos entre participantes, inibindo a participação daqueles mais desacostumados com interações online.

Este cenário se torna ainda mais específico quando se trata do ensino da habilidade da fala em Língua Inglesa. Os comentários (feedback) do professor desempenham um papel crítico para os alunos da $\mathrm{EaD}$, não apenas como uma resposta à performance deles, mas também pela manutenção do suporte, do encorajamento e da motivação:

\footnotetext{
Dentro de um ambiente de sala de aula, os alunos de línguas podem fazer alguns julgamentos sobre seus progressos à medida em que têm acesso às respostas dos outros, às interações em aula e ao monitoramento contínuo e ao feedback do professor. Esses elementos não estão tão disponíveis no ensino à distância, de modo que os alunos buscam feedback por escrito para obter uma noção de sua competência geral. O feedback também é uma parte importante do relacionamento contínuo professor-aluno; contribui para a forma como o aprendiz vê o papel do professor e indica até que ponto o professor está preparado para fornecer apoio individual (WHITE, 2003, p. 187) ${ }^{3}$.
}

A autora propõe a aprendizagem colaborativa como solução para esse desafio. Segundo ela, muitas questões levantadas sobre negociação de feedback e diálogos podem ser aplicadas ao feedback dos pares, diminuindo o tempo de espera pelas respostas e desafogando a demanda dos tutores e professores.

Uma qualidade essencial do alunado da $\mathrm{EaD}$ que precede a aprendizagem colaborativa entre os pares é a autonomia do aluno no processo de ensino e aprendizagem (LEFFA, 2016; REINDERS, WHITE, 2016), o estágio em que o aluno gerencia a si próprio, regulando suas necessidades e o seu desejo de aprender. Traçando um paralelo com a $\mathrm{EaD}$, existem algumas restrições de ordem prática: há um período de encantamento nas primeiras aulas, mas o interesse normalmente cai depois. Os alunos

\footnotetext{
${ }^{3}$ Tradução nossa.
} 
percebem que aprender uma língua estrangeira requer esforço e persistência; alguns se preocupam em conseguir uma nota para aprovação, ou em aprender frases funcionais.

Assim como os alunos vivenciam adaptações ao aderirem a programas de $\mathrm{EaD}$, os professores também fazem parte do processo de estimulá-los a ser autônomos e a desenvolver autoconfiança. Eles devem se familiarizar com as tecnologias e com novas formas de se relacionar com os discentes, inclusive fazendo sair de cena a figura do docente enquanto autoridade máxima que controla os conhecimentos e deixar entrar o papel de "facilitador da aprendizagem" (LEFFA, 2016, p. 297), expondo-se a todos os tipos de questões que possam surgir (não apenas àquelas que ele sabe responder de prontidão). Afinal, mediante a restrição de contato presencial, como professores, tutores e alunos trabalham as habilidades orais na Licenciatura em Letras - Língua Inglesa, na UFC Virtual? Na seção seguinte, tratamos sobre os recursos de interação disponíveis no Solar, e analisamos as tarefas de produção oral propostas pelo curso.

\section{RECURSOS DE INTERAÇÃO NA APRENDIZAGEM DE INGLÊS NA UFC VIRTUAL}

Quando se trata da necessidade de comunicação entre os agentes da Educação a Distância, é essencial tratarmos sobre os conceitos de interações síncrona, assíncrona e multissíncrona mencionados por White (2003). Para a autora, a maior parte da aprendizagem a distância ocorre quando os sujeitos estão em locais diferentes. Nesse caso, a comunicação em plataformas tecnológicas pode ser feita de três formas: síncrona, quando as oportunidades de aprendizagem são combinadas com hora marcada; assíncrona, quando a troca de informações envolve recursos que podem ser acessados a qualquer momento pelo usuário (através de e-mails, fóruns, videoaulas); ou multissíncrona, que é a combinação de mídias de forma a aproveitar as vantagens de cada uma, fazendo com que se complementem.

Os recursos assíncronos têm como objetivo flexibilizar o acesso dos aprendizes ao conteúdo do curso, com a vantagem do baixo custo para a instituição e para os participantes, uma vez que eles não estão confinados a horários específicos. Do outro lado, existe o conceito de interação síncrona, que seria o uso de tecnologias para 
comunicação em tempo real. Nesse tipo, os horários dos encontros são préestabelecidos, tornando esses recursos opções menos flexíveis, mas não menos eficientes. Sistemas síncronos podem ser motivantes para que os alunos da EaD se sintam menos isolados e ganhem energia e inspiração a partir da aprendizagem em grupo. Isso porque podem se assemelhar às conversações ao vivo e têm caráter mais natural. Os comentários dos professores (feedback) ocorrem de forma imediata nesse processo, o que permite mais oportunidades de desenvolvimento dos alunos.

O AVA Solar, do Instituto UFC Virtual, disponibiliza material online multimídia de fácil navegação, contendo textos, ilustrações, vídeos, áudios e infográficos, para que alunos de graduação da instituição estudem as lições de cada disciplina. Ao acessar o Solar mediante a apresentação de um código de usuário e senha, o aluno encontra um painel contendo as disciplinas nas quais está matriculado naquele semestre e seleciona em qual pretende navegar.

No painel da disciplina Língua Inglesa 3A, o usuário tem acesso a links nas seguintes seções: Conteúdo (subdividida nas abas Aulas e Material de Apoio); Atividades (subdividida em Fórum, Porftólio, Prova, Acompanhamento, Chat e Webconferência); Informações Gerais (Programa, Agenda, Bibliografia e Participantes); Mensagens e Matrícula. 


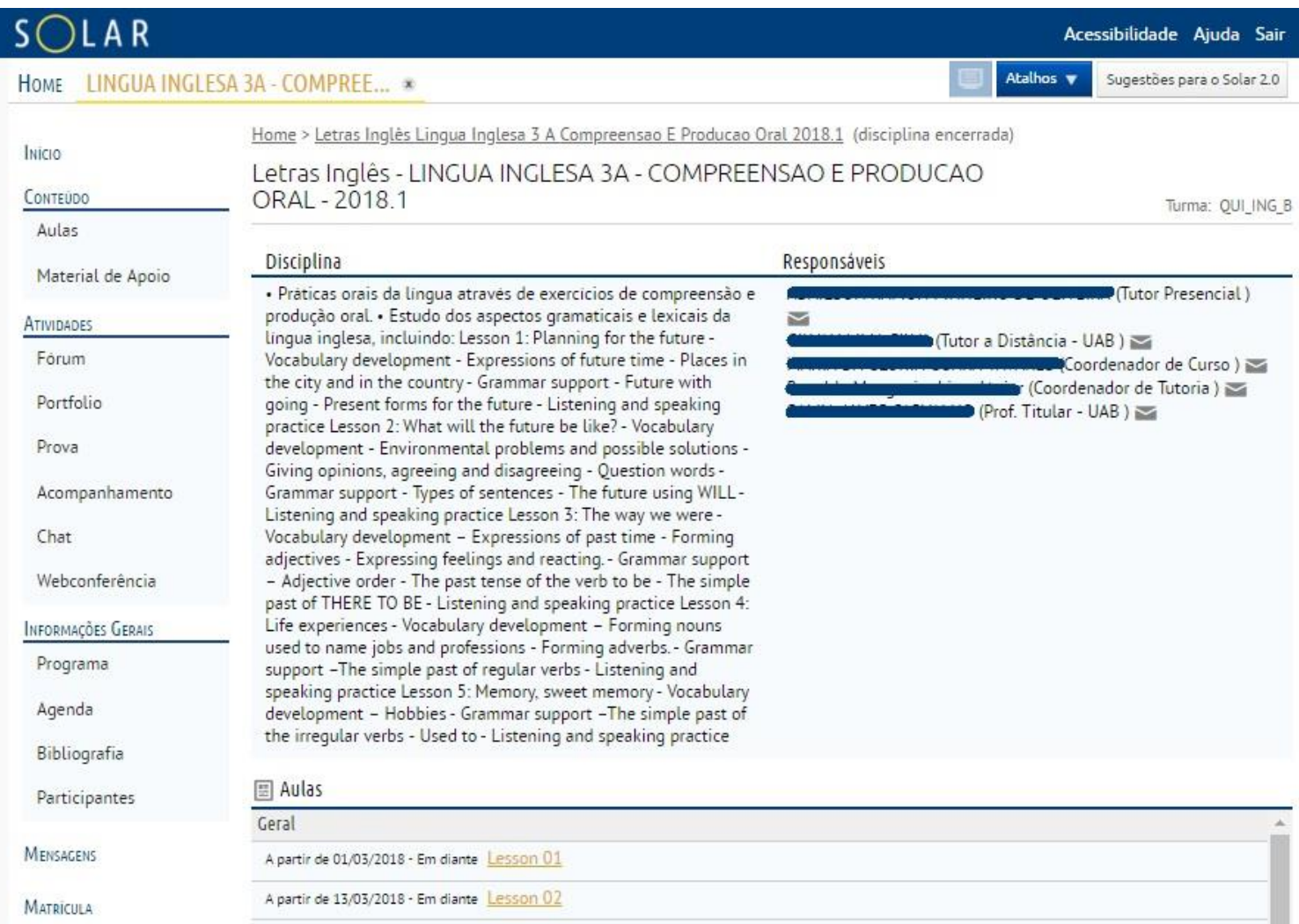

Figura 1 - Ambiente Virtual de Aprendizagem Solar (UFC, 2018)

Durante o período no qual acompanhamos as atividades da disciplina no Solar, constatamos que a maior parte das interações não acontecia em tempo real. Foram disponibilizados os seguintes espaços para comunicação assíncrona: a) Fórum, onde foram lançadas listas de discussões nas quais o tutor a distância lançou temas para debates escritos, e os estudantes puderam trocar ideias dentro de um período préestabelecido; b) Mensagens, a caixa de e-mails por onde os participantes do curso (alunos, tutores, professores, coordenadores e técnicos) podiam enviar mensagens entre si; c) Portfólio, espaço por onde os alunos enviaram suas tarefas para que os tutores as avaliassem. Nesse último, o tutor registrou as notas dos aprendizes e comentou, individualmente, os desempenhos nas atividades.

A comunicação em tempo real (síncrona) foi um recurso pouco usado no Solar ao longo da disciplina avaliada, o que aponta para a dificuldade de estabelecer horários nos quais todos os alunos possam estar juntos no AVA, considerando que muitos optam pela $\mathrm{EaD}$ por terem pouco tempo livre para aulas presenciais. As ferramentas desta natureza encontradas no Solar foram os bate-papos escritos (Chats) e as 
videoconferências (Webconferences), que podiam ter conversações via áudio, vídeo, apresentações de conteúdos e trocas de mensagens digitadas. Nenhuma das duas opções, no entanto, foi utilizada pelo tutor da disciplina ao longo do período acompanhado em nossa pesquisa.

As videoconferências poderiam oferecer momentos de instrução em tempo real, o que seria importante para o desenvolvimento das competências orais dos alunos, tais como a compreensão e a produção oral (listening e speaking). Através delas, seria possível ouvir o tutor e outros colegas, corrigir pronúncia e receber correções ou comentários (feedback) mais precisos do tutor. Contudo, observamos que a comunicação escrita foi priorizada no Solar em detrimento da comunicação oral.

O conteúdo da disciplina foi dividido em cinco aulas (Lessons), com duração de doze dias cada, nas quais os alunos podiam ler conteúdos, ouvir áudios para conhecer as pronúncias de palavras pertencentes ao vocabulário relacionado aos temas e acessar vídeos para ampliar seus conhecimentos sobre os assuntos. A frequência foi calculada com base nas participações nas atividades online e presenciais. Além das aulas virtuais, houve duas aulas presenciais, as quais não foram analisadas nesse trabalho.

As tarefas à distância consistiram na participação em um Fórum Geral TiraDúvidas e na entrega de Portfólios. No primeiro espaço, foram debatidos alguns assuntos sobre tempos verbais (tenses) e realizadas pequenas tarefas. Já na área de Portfólio, foram lançadas dez atividades avaliativas de produção oral em LI (speaking), sendo cinco individuais e cinco em dupla. As individuais consistiram na gravação de áudios contendo discursos curtos em Língua Inglesa, nos quais os alunos deveriam falar sobre experiências pessoais do passado e expectativas para o futuro. As gravações em dupla, que poderiam ser feitas pessoalmente ou a distância (mediante uso de aplicativos em smartphones), deveriam ter o formato de conversações e/ou entrevistas entre alunos, motivadas por temas lançados para cada atividade, tendo como conteúdos norteadores tempos verbais do passado e do futuro.

Levando em consideração as propostas de Paiva (2013) para motivar os alunos com atividades interativas mais atraentes, avaliamos como positivas as propostas de tarefas encontradas no Solar, pois os alunos foram incentivados a falar sobre suas próprias vidas e a dar suas opiniões sobre temas atuais. Essa iniciativa retira de cena a descontextualização de conteúdo tão criticada nos materiais didáticos de ensino de LI. 
SPEAKING PRACTICE

AULA 3

Caro aluno,

Esta parte traz uma atividade de interação mais livre entre você e um colega de turma através do $S K Y P E$. Você deverá combinar com SEU buddu um dia e hora para estar online e juntos realizarem a tarefa proposta para a aula. Lembre-se de que vocês deverão gravar esse diálogo e enviar para seu tutor. Você poderá escolher entre as tarefas A e B. Reaja aos comentários dos colegas.

Choose task A or task B. Try to react to your friend's comments using expressions to react to something good; expressions to react to something surprising; expressions to react to something disagreeable.

TASK A - Facts about your life

Here are some questions you may ask to talk about your childhood.

- Were you a/an obedient/disobedient/ happy/bad-tempered/ well behaved/ friendly/lazy/stubborn child?

- Were you good in school?

- How were you as a student?

- Who was your best friend in school?

- What was he/she like?

- How was your first school?

- What was the name of your first teacher?

- What was he/she like?

- What was your favorite subject in school?

- Where were you born?

- What was your best birthday?

- What was your most favorite toy/game/food/drink?

- What were your hobbies as a child?

- What were parents' occupations when you were a child?

Figura 2 - Instruções para prática de speaking da Aula 3 (UFC, 2018)

Retornando às tarefas de speaking no Solar, todas solicitaram aos alunos que transferissem arquivos para seus computadores, fizessem gravações falando em LI e enviassem os arquivos respondidos. Nas cinco tarefas individuais, havia o seguinte enunciado: "Fazer download do arquivo, responder e enviar para o portfólio". Nas cinco atividades em duplas, o enunciado usado foi: "Fazer download de orientações sobre a atividade oral, fazer a atividade oral, gravá-la e enviar para o portfólio”.

Todos os arquivos disponibilizados para as cinco tarefas individuais tinham roteiros, segundo os quais os alunos deveriam completar textos com as palavras adequadas gramaticalmente e lê-los em voz alta, enviando posteriormente a gravação ao AVA para que o tutor a distância fizesse a avaliação de speaking da semana. Também foi solicitado que os alunos escrevessem parágrafos sobre determinados temas e gravasse a leitura em voz alta, conforme o seguinte enunciado da atividade da Aula 3: "Escreva sobre a sua cidade na época em que você era criança. Lembre-se de usar o verbo to be e there to be no pretérito, e adjetivos para tornar sua descrição mais 
interessante. Depois, grave seu parágrafo e o envie ao seu tutor". O arquivo com as respostas escritas deveria ser enviado ao tutor com as gravações.

Com relação às cinco tarefas em duplas, todas começaram com o seguinte o enunciado: "Esta parte traz uma atividade de interação mais livre entre você e um colega de turma através do SKYPE. Você deverá combinar com SEU buddy um dia e hora para estar online e juntos realizarem a tarefa proposta para a aula. Lembre-se de que vocês deverão gravar esse diálogo e enviar para seu tutor"4.

Em seguida, foram apresentados roteiros com perguntas e respostas para nortear a interação entre os interlocutores, conforme o tema proposto. Com base nestas sugestões, os alunos desenvolveram suas conversações. Reproduzimos, aqui, a nossa tradução de algumas das instruções fornecidas em inglês no Portfólio em dupla da Aula 1: "Aqui estão algumas perguntas que você pode fazer para descobrir sobre os planos do seu amigo para o fim de semana: 'Você está indo... viajar? Ficar em casa? Ver um filme? Ler um livro? Sair com amigos?",5. Mais abaixo, seguiram sugestões de respostas: "Aqui estão alguns comentários que você pode fazer sobre os planos do seu amigo para o fim de semana: - Fantástico! - Interessante! - Ótimo! - Que entediante! Coitado!"6. Depois de responder as tarefas em arquivos Word, os alunos deveriam anexá-los aos seus respectivos Portfólios no Solar junto com as gravações.

Constatamos, então, que os alunos tinham duas opções ao gravar os monólogos das atividades individuais e os diálogos das tarefas em duplas: poderiam ser naturais durante as gravações, conversando conforme o fluxo das ideias e corrigindo os erros à medida que eles aconteciam; ou poderiam planejar as falas, inclusive escrevendo o que pretendiam dizer - conforme as instruções. Assim, estariam lendo diálogos escritos e simulando uma conversação.

Resgatamos, aqui, o problema suscitado por Oliveira (2015): a leitura oral em Língua Inglesa pode ser considerada produção oral? Para o autor, a resposta é não. Leitura, fala, escuta e escrita são habilidades frutos de processos diferentes que se

\footnotetext{
${ }^{4}$ Grifos do autor do material disponível no arquivo lesson_1_aba_5_speaking_practice.doc, enviado para os alunos na área 'Material de Apoio', do Solar.

${ }^{5}$ Tradução nossa. Citação original: "Here are some questions you may ask to find out about your friend's plans for the weekend: - Are you going to... travel? Stay home? See a movie? Read a book? Go out with friends?".

${ }^{6}$ Tradução nossa. Citação original: "Here are some comments you may say about your friend's plans for the weekend: - Fantastic! - Interesting! - Great! - How boring! - Poor you!"”
} 
complementam. O que é mais espontâneo no discurso falado - contendo repetições, adições e marcadores de interatividade - torna-se mais preciso na escrita. Fala e escrita apresentam diferentes níveis de complexidade, o que pode ser avaliado na natureza das orações (BROWN; LEE, 2015). A tendência dos falantes é elaborar orações simples e curtas, com conectores coordenativos que os levam à redundância e repetição para serem claros. Na escrita, as orações podem ser mais longas, fazendo referências a outros elementos no texto. Ao ler textos escritos, o estudante perde também a naturalidade da fala e da negociação de sentidos, deixando de se engajar no diálogo de forma criativa conforme surgem assuntos com seu interlocutor. Para ter proficiência oral, é preciso compreender e interagir de forma a ser compreendido.

Sobre o feedback tutorial das atividades, todas elas foram avaliadas pelo tutor a distância. Reinders e White (2016) e Brown e Lee (2015) ressaltam que comentários e correções são bastante úteis para a aprendizagem da fala em LI, pois os alunos podem ampliar seus conhecimentos. Lima (2013) defende que a correção de pronúncia não precisa ocorrer de forma excessiva, mas pontual, com professores fazendo observações pertinentes para que os aprendizes não cometam erros que transmitam um significado diferente do pretendido originalmente. Desta forma, evita-se comprometer a compreensão do ouvinte.

O feedback do tutor, no entanto, não ocorria de forma sincrônica no Solar; os alunos aguardaram algumas semanas até receber os comentários sobre as atividades dentro da área de Portfólio. Assim, a agenda da disciplina não incluiu encontros virtuais em tempo real para que o tutor escutasse os alunos conversando em inglês. Tais interações entre os alunos e o tutor ocorreram apenas em dois encontros presenciais, quando o tutor teve a oportunidade de fazer correções imediatas sobre aspectos fonéticos, fonológicos, de entonação e de ritmo do discurso.

Por fim, chegamos às seguintes afirmações: a) os momentos de interações orais sincrônicas entre os alunos e o tutor da disciplina Língua Inglesa 3A resumiram-se a dois encontros presenciais; b) não aconteceram encontros online em tempo real, mesmo com a existência da ferramenta de webconferência no Solar. Os alunos, então, tiveram pouco tempo para praticar oralidade em conversações em tempo real entre si e com o tutor, bem como para tirar dúvidas e ter feedback do tutor sobre seus desempenhos, conforme sumarizamos a seguir. 


\section{CONSIDERAÇÕES FINAIS}

Nesse trabalho, investigamos como ocorreu o desenvolvimento da produção oral em Língua Inglesa no curso de Licenciatura Plena em Letras - Língua Inglesa e suas Literaturas, do Instituto Universidade Virtual (UFC Virtual). Para isso, fizemos uma análise das tarefas de speaking solicitadas na disciplina de Língua Inglesa Compreensão e Produção Oral, do terceiro semestre do curso.

Analisando o AVA Solar, identificamos que a maior parte das interações entre alunos e tutores ocorreu de forma assíncrona, em dias e horários diferentes. Também constatamos que os recursos de interação oral síncrona disponíveis na ferramenta, tais como a sala de bate-papo e o espaço para webconferência ao vivo, não foram utilizados ao longo do período letivo acompanhado. Vimos que a proposta da instituição para trabalhar a oralidade dos alunos consistiu na participação em atividades que solicitavam as gravações de depoimentos individuais e de entrevistas em pares. Consequentemente, os comentários do tutor a distância, sobre pronúncia, ritmo e entonação no discurso dos aprendizes, também não ocorreram sincronicamente, pois as anotações foram inseridas pelo tutor no sistema algumas semanas após o envio das atividades por parte dos alunos. As duas aulas presenciais, portanto, foram as oportunidades nas quais os alunos falaram em inglês em tempo real com toda a turma e o tutor.

Para que a instituição possa aperfeiçoar seus métodos e ferramentas no auxílio à aprendizagem dos alunos, sugerimos, como alternativa aos encontros presenciais no polo, a utilização do Solar com mais frequência para a comunicação sincrônica a distância através das webconferências, ou de sessões de bate-papo com o tutor para tirar dúvidas. Podem surgir, nestes momentos, ricas trocas de ideias e novas oportunidades de práticas de speaking.

Dentro da realidade do ensino semipresencial, investir em uma maior quantidade de aulas presencialmente poderia ser arriscado devido às restrições típicas que os próprios alunos da $\mathrm{EaD}$ vivenciam para conciliar os estudos com suas rotinas de trabalho e de afazeres domésticos. Desse modo, seria possível que estudantes e tutores se encontrassem em um ambiente virtual para discutir e conversar em LI, recebendo feedbacks mais imediatos sobre pronúncia e fluência. Caso necessário, as 
administrações dos polos municipais também poderiam participar da organização de webconferências em seus Laboratórios de Informática para alunos que estivessem com qualquer problema de acesso à Internet. Tal iniciativa é mencionada como sugestão no Projeto Pedagógico do Curso, mas não foi praticada no decorrer da disciplina. É preciso reconhecer, portanto, que a alternativa mais viável seria o agendamento das webconferências para que cada estudante participe estando em casa.

\section{REFERÊNCIAS BIBLIOGRÁFICAS}

BRASIL. Decreto n. ${ }^{\circ}$ 9.057, de 25 de maio de 2017. Regulamenta o art. 80 da Lei n. ${ }^{\circ}$ 9.394, de 20 de dezembro de 1996, que estabelece as diretrizes e bases da educação nacional. Diário Oficial da União, Poder Executivo, Brasília, DF, 2017a. Disponível em: <https://goo.gl/po2DGN>. Acesso em 06 out. 2018.

Lei n. ${ }^{\circ} 13.415$, de 16 de fevereiro de 2017. Altera a Lei n. ${ }^{\circ} 9.394$, de 20 de dezembro de 1996, e dá outras providências. Diário Oficial da União, Poder Executivo, Brasília, DF, 2017b. Disponível em: 〈https://goo.gl/GHWnE9>. Acesso em 06 jul. 2018.

Decreto n. ${ }^{\circ}$ 5.622, de 19 de dezembro de 2005. Regulamenta o art. 80 da Lei no 9.394, de 20 de dezembro de 1996, que estabelece as diretrizes e bases da educação nacional. Diário Oficial da União, Poder Executivo, Brasília, DF, 2005. Disponível em: 〈https://goo.gl/i5ptiR>. Acesso em 06 out. 2018.

Lei n. ${ }^{\circ}$ 9.394, de 20 de dezembro de 1996. Estabelece as diretrizes e bases da educação nacional. Diário Oficial da União, Poder Executivo, Brasília, DF, 1996. Disponível em: 〈https://goo.gl/RpwkTV>. Acesso em 06 out. 2018.

BROWN, H. D; LEE, H. Teaching by principles: an interactive approach to language pedagogy. 4. ed. White Plains, NY: Pearson Education, 2015.

GIL, A. C. Como elaborar projetos de pesquisa. 6. ed. São Paulo: Atlas, 2017.

HACK, J. R.; NEGRI, F. Escola e tecnologia: a capacitação docente como referencial para a mudança. Revista Ciências \& Cognição. Rio de Janeiro: UFRJ. Vol. 15(1), mar. 2010, p. 89-99. Disponível em: <https://goo.gl/x5oHn4>. Acesso em 09 ago. 2018.

LAKATOS, E. M; MARCONI, M. A. Fundamentos de metodologia científica. 8. ed. São Paulo: Atlas, 2017.

LEFFA, V. J. Língua estrangeira: ensino de aprendizagem. Pelotas: EDUCAT, 2016. 
LIMA, J. R. Correção da pronúncia e a identidade do aluno de letras. In: LIMA, D. C. (Org.). Ensino e aprendizagem de língua estrangeira: conversa com especialistas. São Paulo: Parábola Editorial, 2013. p. 69 - 78.

OLIVEIRA, L. A. Aula de inglês: do planejamento à avaliação. São Paulo: Parábola Editorial, 2015.

PAIVA, V.L.M.O. O ensino de língua estrangeira e a questão da autonomia. In: LIMA, D. C. (Org.). Ensino e aprendizagem de língua estrangeira: conversa com especialistas. São Paulo: Parábola Editorial, 2013. p. 31 - 38.

Aprendendo inglês no ciberespaço. Interação e aprendizagem em ambiente virtual. Belo Horizonte: Faculdade de Letras, UFMG, 2001. p. 270 - 305. Disponível em: 〈https://goo.gl/D1ALKY〉. Acesso em 02 jul. 2018.

O papel da educação a distância na política de ensino de línguas. In: MENDES et ali (Orgs.). Revisitações. Belo Horizonte: UFMG/FALE, 1999 (p. 41 - 57).

Disponível em: <http://www.veramenezes.com/ead.htm>. Acesso em: 24 jul. 2018.

REINDERS, H.; WHITE, C. 20 years of autonomy and technology: how far have we come and where to next? In: Language Learning \& Technology. Vol. 20, n. 2, jun. 2016, p. 143 -154. Disponível em:

<http://llt.msu.edu/issues/june2016/reinderswhite.pdf>. Acesso em 13 jul. 2019.

SHELLEY, M.; MURPHY, L.; WHITE, C. Language teacher development in a narrative frame: The transition from classroom to distance and blended settings. In: System. Vol. 41, n. 3, set. 2013, p. 560 - 574. Disponível em: < https://doi.org/10.1016/j.system.2013.06.002>. Acesso em 13 jul. 2019.

UNIVERSIDADE FEDERAL DO CEARÁ (UFC). Solar: Ambiente Virtual de Aprendizagem. Fortaleza: UFC, 2018. 2 ilustrações (capturas de tela). Disponível em: <http://solar.virtual.ufc.br>. Acesso em 05 out. 2018.

Projeto pedagógico do curso de licenciatura em Letras: Língua Inglesa e suas literaturas (modalidade à distância). Fortaleza: UFC, 2013. Disponível em: <https://goo.gl/GqrZgW>. Acesso em 02 jul. 2018.

WHITE, C. Language learning in distance education. Cambridge: Cambridge University Press, 2003. 


\section{Karoline Zilah Santos}

Especialista no Ensino de Língua Inglesa pela Universidade Estadual do Ceará (Fortaleza/Brasil). Graduanda em Letras - Língua Inglesa e suas Literaturas, pela Universidade Federal do Ceará (Fortaleza/Brasil). Bacharel em Comunicação Social (habilitação em Jornalismo) pela Universidade Federal da Paraíba (João Pessoa/Brasil). Professora-bolsista de Língua Inglesa no Programa Idiomas sem Fronteiras, na Universidade Federal do Ceará

\section{Karlucy Farias de Sousa}

Mestre em Linguística Aplicada (Concentração em Estudos da Linguagem) pela Universidade Estadual do Ceará (Fortaleza/Brasil). Pós-graduanda em Linguagem, Tecnologia e Ensino pela Universidade Federal de Minas Gerais (Belo Horizonte/Brasil). Professora de Língua Inglesa do Instituto Federal de Educação, Ciência e Tecnologia do Ceará (IFCE-Campus Limoeiro do Norte).

Artigo recebido em 11/02/2019

Aceito para publicação em 24/07/2019

\section{Para citar este trabalho:}

SANTOS, Karoline Zilah; SOUSA, Karlucy Farias de. APRENDENDO INGLÊS A DISTÂNCIA: UMA ANÁLISE DE PRÁTICAS DE SPEAKING NA LICENCIATURA EM LETRAS PELA UFC VIRTUAL. Revista Paidéi@. Unimes Virtual. Volume 11 - Número 20 - JULHO - 2019 - Disponível em:

http://periodicos.unimesvirtual.com.br/index.php/paideia/editor 